\title{
Correction to: Concurrent vitamin D supplementation and exercise training improve cardiac fibrosis via TGF- $\beta / S m a d$ signaling in myocardial infarction model of rats
}

\author{
Mohammad Mehdipoor $^{1}$ - Arsalan Damirchi ${ }^{1}$ - Seyed Mohammad Taghi Razavi Tousi ${ }^{2,3} \cdot$ Parvin Babaei ${ }^{3,4}$ \\ Published online: 13 March 2021 \\ (C) University of Navarra 2021
}

\section{Correction to: Journal of Physiology and Biochemistry} https://doi.org/10.1007/s13105-020-00778-6

The original version of this article unfortunately contained an incorrect order of affiliation(s) for Author Parvin Babaei from 3,4 to 4,3 . The first affiliation should be Cellular \& Molecular Center, School of Medicine, Guilan University of Medical Sciences.

Publisher's note Springer Nature remains neutral with regard to jurisdictional claims in published maps and institutional affiliations.

The online version of the original article can be found at https://doi.org/ 10.1007/s13105-020-00778-6

Parvin Babaei

p_babaei@gums.ac.ir

1 Department of Sport Physiology, Faculty of Physical Education and Sport Sciences, University of Guilan, Rasht, Iran

2 Cardiovascular Diseases Research Center, Heshmat Hospital, Department of Cardiology, Guilan University of Medical Sciences, Rasht, Iran

3 Cellular \& Molecular Research Center, School of Medicine, Guilan University of Medical Sciences, Rasht, Iran

4 Dept of Physiology, School of Medicine, Guilan University of Medical Sciences, Rasht, Iran 